\title{
Aspectos diacrônicos nos estudos sufixais
}

Diachronic aspects in suffixal studies

Érica Santos Soares de Freitas ${ }^{1}$

Resumo: Apresentaremos, neste artigo, a metodologia de pesquisa empregada para estudos diacrônicos sobre sufixos, de acordo com métodos criados no Grupo de Morfologia Histórica do Português (GMHP), grupo de pesquisa criado em 2004, e do Núcleo de Apoio à Pesquisa em Etimologia e História da Língua Portuguesa (NEHiLP), núcleo de pesquisa criado em 2013, liderados pelo Dr. Mário Eduardo Viaro e sediados na Faculdade de Filosofia, Letras e Ciências Humanas (FFLCH) da Universidade de São Paulo (USP). A pesquisa foi feita analisando o sufixo -mentum latino e seus derivados nas línguas castelhana (-mento/-miento), francesa (-ment), italiana (mento), romena (-mânt/-ment) e portuguesa (-mento/-menta). Apresentamos a formação dos corpora utilizados e, ao final, o resultado das análises feitas.

Palavras-chave: diacronia; morfologia diacrônica; sufixação; sufixo -mento.

\begin{abstract}
We present, in this article, the research methodology used for diachronic studies suffixes, according to methods created in the Historical Morphology Group Portuguese (GMHP), a research group created in 2004, and the Center for Research Support in Etymology and History Portuguese Language (NEHiLP), research center created in 2013, led by Dr. Mario Eduardo Viaro and based in the Faculty of Philosophy, Letters and Human Sciences (FFLCH), University of São Paulo (USP). The research was done by analyzing the Latin suffix -mentum and its derivatives in Spanish (-mento / -miento), French (-ment), Italian (-mento), Romanian (-mânt / -ment) and Portuguese (-mento / -menta). We present the formation of corpora used and, at the end, the result of the analysis made.
\end{abstract}

Keywords: diachrony; diachronic morphology; suffixation; -mento suffix.

\footnotetext{
1 Doutora em Filologia e Língua Portuguesa e Pós-doutoranda (Processo Fapesp 2014/12543-1), Universidade de São Paulo, Brasil. ericafreitas@usp.br.
} 


\section{Introdução}

Nosso trabalho é direcionado ao estudo morfológico diacrônico, entretanto como dependemos dos estudos de outras ciências, como a Filologia, a Ecdótica, a Crítica Textual, a Lexicologia e a Lexicografia, e a Semântica, não podemos nos limitar à análise morfológica pura.

Utilizamos, nesse trabalho, o termo 'palavra' com o significado geral de 'palavra lexical', isto é, portadora de significado lexical e categorizável numa das classes maiores da gramática (substantivo, adjetivo, verbo ou advérbio), com o intuito de observarmos sua formação e significado, assim como seu uso contextual (ou, talvez, a falta dele).

Embora haja diversos estudos sobre sufixos, sabemos que grande parte se limitou, no geral, em relacionar os significados individuais assumidos ao longo do seu desenvolvimento. Com muito menos intensidade debruçouse sobre sua genealogia, suas origens e muitas das suas características, não apenas as semântico-funcionais. Sem dúvida, permanecerá um problema extremamente difícil e, na maior parte, insolúvel encontrar os motivos pelo quais uma língua modificou, por exemplo, o significado de um sufixo, expandindo ou limitando seus elementos semânticos ou the banindo completamente o primeiro sentido atribuído. Pode-se, no entanto, ordenar suas modificações, de acordo com a sua sucessão temporal, a fim de apresentar, desse modo, alguns indícios para o processo de determinada língua.

No âmbito das pesquisas do Grupo de Morfologia Histórica do Português (GMHP) e do Núcleo de Apoio à Pesquisa em Etimologia e História da Língua Portuguesa (NEHiLP), ambos liderados pelo Prof. Dr. Mário Eduardo Viaro, nosso estudo debruça-se nos aspectos diacrônicos, semânticos e etimológicos do sufixo latino -mentum, de sua formação a partir do sufixo -men, e dos derivados pelos seus equivalentes nas línguas românicas, as quais compartilham o latim em sua gênese, norteando-se pelo conceito de que, conforme Viaro (2006c), o significado da base é diferente do significado do sufixo e da acepção da palavra formada pela derivação por meio deste.

A língua é parte essencial da cognição humana. A Semântica observa a relação entre língua e pensamento, e de que maneira essas conexões se realizam para a construção da significação. É fato que estudar um grupo de derivados caracterizado por um dado instrumento de derivação pode ter dois lados: o elemento de derivação considerado para formar palavras e a relação semântica existente entre a designação do nome ${ }^{2}$ e o $\operatorname{ser}^{3}$ nomeado; a relação semântica da própria derivação, de outra ordem, porque exclui a relação direta: as palavras devem ser instrumentos de designação e operam de acordo com uma terminologia.

Além disso, para uma língua funcionar, este elemento derivativo forma palavras carregadas de significado; contudo, se o estudo semântico desse elemento cria uma unidade da classe, devemos observá-las, portanto, de acordo com a caracterização das palavras semanticamente comuns, tomando como objeto específico a própria semântica do elemento de derivação e verificando como esse item modifica a noção expressa pela base sobre a qual ele se encaixa.

Há, portanto, nas palavras derivadas uma relação interna entre o conteúdo semântico do elemento de derivação, da base e da palavra formada. Dubois indica que uma unidade só recebe significação da existência por meio de outros termos da língua, que a delimitam e a contradizem (DUBOIS, 2001 [1973], p. 453). Concorda, portanto, com Saussure (1995), indicando seu exemplo da palavra enseignement, a qual possui uma relação paradigmática com outras palavras, seja por meio do radical, do sufixo-ment (-mento), do significado ou, inclusive, da rima (fonética):

\footnotetext{
${ }^{2}$ Cabe aqui informar que se utilizou a nomenclatura de 'nome' para o grupo de palavras que se opõe ao 'verbo' pelo valor estático de seus semantemas. O nome indica as 'coisas', quer se trate de objetos concretos ou de noções abstratas, de seres reais ou de espécies. O verbo indica os 'processos', quer se trate de ações, de estados ou de passagem de um estado a outro. (MEILLET, 1948).

3 'Ser' foi utilizado em um sentido amplo, incluindo objetos abstratos e concretos.
} 
Ainsi le mot enseignement fera surgir inconsciemment devant l ésprit une foule d'autres mots (enseigner, reseigner, etc, ou bien armement, changement etc., ou bien éducation, apprentissage); par un cotê ou un autre, tous ont quelque chose de commun entre eux ${ }^{4}$. SAUSSURE, 1995 [1916], p. 171.

No "Curso de Línguística Geral", atribuído a Saussure, a relação mental que o falante cria pode gerar outros grupos, além daqueles que têm uma base comum (raiz ou radical), produzindo outras relações, por exemplo por meio de um sufixo:

Ainsi dans enseignement, enseigner, enseignons, etc., il y a un élement commun à tous les termes, le radical; mais le mot enseignement peut se trouver impliqué dans un série basée sur un autre élement comum, le suffixe (cf. enseignement, armament, changement, etc). (...) Donc il y a tantôt communauté double du sens et de la forme, tantôt communauté de forme ou de sens seulement ${ }^{5}$. SAUSSURE, 1995 [1916], pp. 173-4.

Desta forma, criaremos uma metodologia de pesquisa, a fim de observarmos como o sufixo -mentum latino se comporta no latim e nas demais línguas latinas escolhidas para serem analisadas não só em relação à morfologia, mas principalmente à semântica, ou seja, os sentidos que ele produz nas palavras a que se associa.

Em muitas línguas, há diversos sufixos que admitem vários sentidos, mais de uma interpretação. Isso posto, nosso trabalho insere-se numa investigação ampla ${ }^{6}$, a fim de analisarmos a formação do sufixo - mentum latino e, desta, aprofundarmos os estudos dos substantivos derivados nos sufixos latinos -men e -mentum.

Portanto, um dos objetivos desta pesquisa foi investigar a origem do sufixo -mentum latino, cujo escopo comprova a hipótese de sua formação advir de dois sufixos: -men e ${ }^{*}$-to. $O$ tema de nosso projeto é uma continuação da pesquisa apresentada em Freitas (2008), na qual apresentamos uma análise minuciosa do sufixo mento na língua portuguesa, sob os aspectos semânticos e estruturais, apenas utilizando as palavras previamente datadas; e Freitas (2014), em que observamos os mesmos aspectos no latim, castelhano, francês, italiano e romeno, contrastando os resultados com aqueles obtidos no português. Além disso, datamos todas as palavras analisadas nos corpora das respectivas línguas, obtendo um resultado muito mais preciso.

Outro objetivo obtido por meio da aplicação desta metodologia foi comprovar a hipótese de que há uma alteração fonológica na base dos verbos de $2^{\text {a }}$ conjugação nas línguas castelhana, italiana e portuguesa, fenômeno que não ocorre na língua francesa, tampouco na romena (pois tem a origem da maioria das palavras neste sufixo, no francês). Com isso, provamos ser a língua francesa diferente das demais línguas românicas também neste aspecto, além de outros apontados em Freitas (2014).

Apontamos, ainda, que as formas advindas do sufixo latino -mentum nas línguas românicas derivam de um aspecto de 'ação de X'. Para isso, faz parte da pesquisa a análise semântica das palavras dos corpora de todas as línguas propostas neste estudo, a fim de comprovarmos essa proposição.

A pesquisa conta com o estudo, de modo exaustivo e diacrônico, da formação de palavras em -mento, no português. Identificamos o sufixo -mento nas palavras encontradas não somente na língua portuguesa, mas também nas demais línguas analisadas neste trabalho, para então observar seus significados e comprovarmos a hipótese de todas serem originadas de uma base verbal, formadas por meio do modelo "base verbal + sufixo mento", com sentido de substantivo, apontando-lhe as paráfrases encontradas.

Tal premissa é baseada no aspecto transitivo (TRS) advindo do latim e que dominou a formação de palavras por meio do sufixo -mentum latino em todas as línguas românicas. Assim, embora essa acepção não fosse a principal na língua latina, foi por meio dela que o sufixo -mentum chegou às línguas românicas, tornando-se a mais produtiva.

\footnotetext{
4 "Assim, da palavra enseignement surgirão inconscientemente à frente do espírito uma porção de outras palavras (enseigner, reseigner, etc, ou armement, changement etc., ou éducation, apprentissage); de qualquer modo, todas têm algo em comum." (Tradução e grifos nossos)

5 "Por exemplo, em enseignement, enseigner, enseignons, etc, há um elemento comum a todos os termos, o radical; mas a palavra enseignement pode estar envolvida em uma série baseada em outro elemento comum, o sufixo (cf. enseignement, armament, changement, etc). (...) Deste modo, há tanto um conjunto de significado e de forma em comum quanto um conjunto de forma e direção iguais. " (Tradução e grifos nossos)

${ }^{6}$ Há estudos esparsos profundos sobre morfologia portuguesa sob o aspecto diacrônico. Em relação a sufixos, então, há poucos trabalhos que abordem esse assunto especificamente, a maioria originários do GMHP e os de Rio-Torto (1993; 1998), por exemplo.
} 
Em Freitas (2008), como informado, pesquisamos somente as palavras com informação de data, cerca de $40 \%$ do corpus total de palavras em -mento, no Português. Já em Freitas (2014), datamos as palavras em -mento portuguesas sem indicação da época de sua criação, para em seguida efetuarmos as análises quantitativa, semânticas e de datação, comprovando a partir dos dados a hipótese de que esse sufixo é produtivo e que há muitas lacunas a respeito do assunto nos séculos XIX e XX. Para isso, inserimos a datação das palavras que não contêm tal indicação, corrigimos outras informadas em Houaiss (2001), retrodatando-as, e incluímos outros verbetes em nosso corpus, encontrados em outras obras lexicográficas de língua portuguesa utilizadas neste trabalho.

A pesquisa iniciou-se com os estudos desenvolvidos pelo GMHP, cujo objeto de trabalho é, dentre outros, desenvolver uma metodologia que reflita e compreenda a formação de palavras, aliando o método sincrônico, por meio da análise das regras de formação de palavras (RFPs), ao estudo diacrônico e etimológico.

Neste trabalho, não analisamos todas as classes de palavras integradas a essa relação; curvamo-nos sobre o significado do sufixo -mentum no latim, a fim de apontarmos a história da língua, a morfologia das palavras, precisas datações e informações etimológicas consistentes na língua portuguesa, devido aos dicionários existentes nesta língua, apesar de bons, não apresentarem com rigor a evolução das palavras, muitas vezes indicando como informação etimológica sua estrutura morfológica ${ }^{7}$. Posteriormente, debruçamo-nos sobre a origem e formação desse sufixo latino, baseando-nos nas hipóteses apresentadas.

Embora indiquemos sua produtividade, seus paradigmas e seus significados por meio da diacronia, há ainda a preocupação de observarmos os sufixos indicados em outras línguas românicas, devido às condições históricas de cada uma. Para isso, a pesquisa foi feita em algumas destas línguas, a saber: português, francês, castelhano, italiano e romeno, como indicado.

A intenção foi, pois, investigarmos o surgimento desse tipo de formação, registrando sua datação e seus significados, a partir de dados obtidos em obras lexicográficas e em sites de referência, como o "Google Books"8,9, poderosa ferramenta de busca, em cujo conteúdo podemos buscar por muitas obras antigas, algumas disponíveis para visualização parcial, muitas com visualização completa, o "Corpus do Português" (CDP) ${ }^{10}$, o "Corpus del Español" (CDE)"11, dentre outros.

Também indicamos a data de quase todas as palavras obtidas dos corpora (com pouquíssimas exceções de palavras não datadas nas línguas francesa e italiana, diferentemente das línguas castelhana, romena e portuguesa, para as quais foi necessária uma pesquisa intensa), a fim de analisarmos as estruturas morfológicas dos verbetes obtidos, por exemplo dos derivados portugueses em - mento, visto que uma parte dessa análise foi feita em Freitas (2008) somente em relação às palavras sufixadas em -mento datadas em Houaiss (2001).

Possivelmente, a formação por sufixação em -mento em palavras portuguesas indicada nos dicionários desta língua tenha ocorrido ainda no latim vulgar, devido a diversos cognatos destas palavras ocorrerem em várias outras línguas românicas, como apartamento, existente nas românicas derivada a partir de uma base apart-: cast. apartamento, cat. apartament, fr. appartement, it. appartamento, rom. apartament, tendo havido empréstimo até para línguas não românicas, mas que fazem parte das línguas indoeuropeias, como o inglês apartment, o holandês appartement, o búlgaro апартамент, o polonês apartament, o albanês apartament; e também para línguas nãoindoeuropeias, como o basco apartamentu, o maltês appartament, o crioulo haitiano apatman, o indonésio apartemen, o malaio apartmen, o tagalo apartment, o telugo apartment. Muitas provavelmente são anglicismos, já

\footnotetext{
7 Em Houaiss (2001), por exemplo, a informação existente no campo "etimologia" do verbete discernimento é: discernir + -mento; ver cern-; f.hist. 1770 descernimento, 1836 discernimento, como se a palavra tivesse sido criada no próprio português por meio da junção do

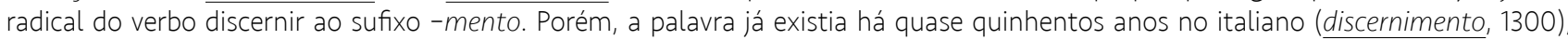
dois séculos antes no francês (discernement, 1532), no castelhano (dicernimiento, s.XV) e, inclusive, no inglês via francês (discernment 1586). É de se estranhar que tenha sido criada no Português tardiamente; com certeza foi emprestada de uma das línguas indicadas.

8 Google Books é um serviço da empresa estadunidense Google que procura textos completos de livros que a Google escaneia, converte-o utilizando o reconhecimento ótico de caracteres, e armazena em seu banco de dados digital. Quando é introduzida uma palavra-chave no sistema de busca, até três resultados do índice do Google Books são disponibilizados sobre os resultados da pesquisa no serviço Google Web Search (google.com). Clicando em um resultado, o Google Books abre uma interface na qual o usuário pode visualizar páginas do livro. O banco de dados do Google Books continua a crescer, permitindo que obras de domínio público e outros materiais sem direitos autorais serem carregados em formato PDF. Disponível em: <http://pt.wikipedia.org/wiki/Google Books>

${ }^{9}$ A título de curiosidade, conseguimos encontrar no Google Books palavras em diversas épocas, retroagindo até o século X $\bar{V}$.

10 Disponível em: <www.corpusdoportugues.org> Acesso em 20 jun. 2015.

${ }^{11}$ Disponível em: <www.corpusdoespanol.org> Acesso em 20 jun. 2015.
} 
que o inglês é uma língua de ampla penetração, porém vemos o quanto uma palavra pode viajar pelo mundo e indicar, em todas essas línguas apontadas, a mesma acepção atualmente: 'habitação, aposento, tipo de imóvel'.

No século $X X$, os estudos sincrônicos, principalmente aqueles fundamentados no estruturalismo e no gerativismo, foram férteis em detrimento dos diacrônicos e históricos (FREITAS; AREÁN-GARCÍA, 2010). Para RioTorto (1998), somente por meio da diacronia podemos analisar determinados aspectos da formação de palavras, por exemplo: a) na identificação do estatuto e dos tipos de constituintes lexicais; b) na clarificação do caráter compósito das palavras; c) no estabelecimento de tipologias de palavras de estrutura complexa; d) na reconstituição da evolução formal e semântica das palavras; e) na explicação de algumas das reestruturações dos sistemas afixais; f) na determinação dos paradigmas genolexicais. Além disso, a contribuição das informações históricas pode ser produtiva para análise dos processos e dos produtos derivacionais, porque "somente por meio do conhecimento da origem e da história de uma palavra é possível caracterizar adequadamente o estatuto morfolexical dos seus constituintes" (RIO-TORTO, 1998, p. 140).

Viaro (2006a; 2006b; 2006c; 2007; 2011) conclui ser necessária uma atitude de complementariedade entre a diacronia e a sincronia. Partindo de uma base verbal, conforme as RFPs, podemos formar o seu infinitivo com o sufixo - ar, e daquela, o nome de um processo ou uma ação, com o sufixo -ção, ou seja, X]ar X]ação. Portanto, uma possível e não contestável aplicação da regra é: separar separação. No entanto, ao aplicamos a mesma regra, teríamos que colação é proveniente de colar, o que é contestado historicamente, pois colação provém do latim collatio, e o verbo colar foi criado posteriormente, a partir de colação (VIARO, 2011, p. 120).

Este é um exemplo que mostra o quanto as línguas podem alterar-se num mesmo tempo, ou seja, podem apresentar variações ocorridas devido a alguns fatores específicos. Logo, não podemos impor o certo e errado quando se trata de desenvolvimento de uma língua; este estudo histórico, como qualquer outro estudo científico, por meio da indução, permite a elaboração de material essencial para a descrição e explicação diacrônica, principalmente etimológica, de sufixos da língua portuguesa.

Parece cousa extremamente fácil dintinguir palavras derivadas de palavras primitivas quando se trata de exemplos (...) que não requerem especial cultivo da intelligência (...) São entretanto numerosos os casos em que transparece menos lúcida a relação entre o termo derivado e o derivante, sendo necessário algum estudo para se perceber a filiação. Outras vezes tem havido tal evolução de forma e sentido, que surge um curioso conflicto entre o pensamento geral do vulgo e o facto encarado à luz da pesquisa scientífica (SAID ALI, 1964 [1930], p. 3).

Portanto, estudamos os vários aspectos das formações derivacionais com o sufixo latino -mentum, a fim de comprovarmos os aspectos semânticos relevantes do sufixo no latim e nas línguas derivadas deste, no caso, as românicas. Nossa pesquisa é feita por meio da indução, e não dedução, ou seja, através de dados empíricos que comprovem nossas hipóteses, a partir da comparação linguística, da etimologia e da datação, bem como das mudanças que, porventura, ocorreram no âmbito linguístico.

Apresentaremos a pesquisa em seções, a saber: pesquisa, contesto histórico, método históricocomparativo, formação dos corpora, análise quantitativa, datação, análise semântica, sufixos concorrentes e considerações finais.

\section{Pesquisa}

Assim como no latim, o sufixo -mento da língua portuguesa possui um concorrente de pouca representação, -me, cujo predecessor latino -men é um dos formadores daquele; contudo, em todas as línguas latinas, das quais o português não é exceção, esse par de sufixos somente possuía aspectos em comum no latim: ao passar para as românicas, eles tomaram caminhos diferentes, e -men, muito pouco produtivo, perdeu força e parou de produzir novas formas.

A primeira hipótese levantada e confirmada foi a de o sufixo latino -mentum ser formado por meio da união de dois sufixos: -men $\mathrm{e}^{*}$-to, este último incorporando ao novo sufixo um aspecto agentivo, observado não somente nas derivadas latinas, mas também nas línguas românicas analisadas. 
Em seguida, observamos as derivações nominais, nas quais incluímos a passagem de -men > -mentum, por verificarmos que este modelo não ocorre nas românicas: as palavras derivadas neste sufixo são quase todas deverbais.

Constatamos, ainda, haver quatro aspectos semânticos nos sufixos latinos observados: TRS, RES, INS e QNT. Diferentemente das línguas latinas, o aspecto RES nas palavras latinas observadas não se originam na acepção TRS, mas ocorre o inverso - é a acepção RES, com mais exemplos indicados, que origina a acepção TRS no latim, visto que aquela trouxe consigo o aspecto de 'resultado da ação de $X$ ' desde o Indoeuropeu.

Assim, a acepção TRS foi transposta para todas as línguas deste estudo, com exceção do romeno, que efetuou empréstimo dessa acepção pelo francês, assim como o de 'lugar' (LCA), aspecto não encontrado em nossos corpora latinos nos sufixos -men e-mentum.

Verificamos outro ponto importante na passagem das acepções semânticas do latim às românicas: o aspecto instrumental entrou nessas línguas exclusivamente por empréstimo - as palavras formadas nas próprias línguas somente repetiram o modelo latino. Contudo, o aspecto quantitativo, ainda que fosse ínfimo no latim, é representativo no português e no castelhano, não só por meio de empréstimos, mas também por produzirem palavras na língua por meio do sufixo - menta, flexão / declinação de plural no latim.

Dentre as línguas românicas, observamos um funcionamento morfológico muito semelhante entre o português, o castelhano e o italiano: todas essas línguas possuem a (ir)regularidade de trocar a vogal temática na derivação de verbos de $2^{\mathrm{a}}$ conjugação. Além disso, diversas palavras foram formadas por meio de formas arcaicas dos verbos que constituem suas bases (port. e cast. entretenimento entreter, de ter < tener; it. traimento trarre, de traere). No francês, há outros aspectos distintivos: a inserção do infixo -iss- nas derivações de verbos do $2^{\circ}$ grupo.

Examinamos em todas as línguas os empréstimos de quase as mesmas palavras latinas em -emento, omento e -umento. Nossa hipótese é a de que essas palavras entraram em determinada língua e desta, ocorreu um outro empréstimo para as demais, em diferentes momentos. Um bom exemplo para incluirmos nessa reflexão é por meio da palavra implement, forma inglesa para a palavra implementum, que surgiu no português em 1731 por empréstimo da língua inglesa e, no francês, também via inglês, somente no século XX. Afirmamos, portanto, que somente pelo modelo indutivo, com corpora confiáveis, é possível fazer uma análise etimológica das palavras. Se não fosse assim, jamais imaginaríamos uma palavra latina entrando no português por meio do inglês no século XVIII, e dois séculos depois entrando no francês, língua de prestígio na época em que surgiu a palavra na língua portuguesa, com movimento contrário no caso observado, visto que o corpus obtido de palavras em -ment na língua inglesa, não mostrado neste trabalho, apresenta muitas palavras francesas ${ }^{12}$.

Ainda sobre empréstimos, verificamos que no romeno $99 \%$ das palavras em -ment se originam no francês, e mesmo com o sufixo - mânt, em que há produções próprias romenas, há alguns casos de empréstimos e, inclusive, decalques. Em relação ao sufixo -mento nesta língua, todas as palavras por ele derivadas são emprestadas.

Sobre a datação das palavras dos corpora românicos, o início é no francês, com as palavras mais antigas formadas no século IX, seguido pelo português, com duas palavras indicadas nos séculos $X$ e XI. Acreditamos que $o$ registro nas demais seja tardio, e que um romance, próximo do que se tornariam as línguas, em cada região, já era falado nessas épocas.

Ao verificarmos os significados de cada sufixo em cada língua, tivemos confirmadas algumas hipóteses levantadas: a) TRS é predominantemente o aspecto com mais exemplos, em todas as línguas; b) a acepção RES resulta da TRS, diferentemente do latim, e traz em si um aspecto agentivo, não só herdado da derivação latina, mas também por contemplar sentimentos, sensações e fatos; c) LCA foi criado nas românicas e é exclusivo dessas línguas; d) QNT foi herdado, em parte, diretamente do latim, por meio do plural de -mentum, -menta13; e) INS, apesar de intenso no latim, foi passado para as românicas por empréstimo, surgindo depois um sufixo -menta com

\footnotetext{
12 Montamos uma lista para analisarmos as palavras inglesas em -ment, mas devido à direção tomada neste estudo, do latim às românicas, reservamos esse corpus inglês, que contém mais de 3.000 exemplos, a maioria decalcada do francês, para um próximo estudo, juntamente com o do provençal.

${ }^{13}$ Acepção que nas obras de referências não possui o aspecto de 'ação', porém na nossa análise as palavras apresentam uma aspecto resultante de 'vários objetos fazendo uma ação de $X^{\prime}$ ', e por extensão de sentido tornam-se um coletivo, em cujo sema há um traço de 'ação',
} 
significado de 'coletivo'. Observamos, ainda, a perda de produtividade de algumas acepções, como a LCA no italiano. Todas essas comprovações foram apresentadas na grande árvore genealógica desenvolvida.

Houve, ainda, necessidade de criarmos duas classes semânticas para as palavras francesas em -ment: CRI e BRU. Observamos que, em francês, esses dois significados são mais produtivos que QNT, LCA e INS, portanto os analisamos e concluímos que estão presentes em diversas épocas da língua, sendo produção própria francesa, e que um dia podem ser produtivos em outras línguas, por analogia ao francês.

Em relação à cognação, havíamos desenvolvido pesquisa intensa em Freitas (2008), por isso não foi refeita para o português (FREITAS, 2014), mas nas outras línguas românicas sim: por um lado, castelhano e italiano comprovam a concorrência histórica do sufixo -mento com o sufixo -ção (e demais formas). No romeno, não há tal sufixo; quem toma seu lugar são as arcaicas formas de infinitivo, derivadas semanticamente para substantivo: are, -ere, -ire, -âre; encontramos, ainda, outros sufixos produtivos em todas as línguas, como -tură (port. -ura / dura / -tura), -nţă (port. -ncia / -nça), -tate (port. -dade).

No francês, novamente verificamos um fenômeno diferente: a cognação esperada em -(t)ion é baixa, visto que o sufixo que mais possui cognatos com -ment é -age, com formação idêntica, regular, inclusive para as bases com inserção do interfixo -iss-, apresentando novamente a língua francesa com papel divergente das demais línguas românicas.

Para encerrarmos, provamos que não há estudos históricos e etimológicos significativos sobre a língua portuguesa nos séculos XIX e XX. Com pesquisa desenvolvida para datarmos cerca de $60 \%$ do corpus em -mento, elevamos para $70 \%$ das formações portuguesas com esse sufixo indicadas nestes séculos, alterando completamente nossa análise semântica e de datação. Confirmamos, portanto, que o sufixo -mento português é produtivo e está em atividade desde os tempos mais remotos até os dias atuais, contrariando parte da bibliografia sobre o assunto, que afirma ser um sufixo arcaico e sem produtividade hoje em dia. Deste modo, embora alguns estudiosos indiquem que o sufixo latino -mentum perdeu produtividade nas línguas românicas nos últimos séculos, principalmente no português, esta pesquisa, ao contrário, evidencia que ele continua formando novas palavras nas línguas modernas, principalmente no português, e até assumindo novas vertentes semânticas, como é o caso das acepções francesas CRI e BRU.

\section{Contexto histórico}

Para contextualizarmos as línguas da pesquisa, fizemos um breve percurso histórico da língua latina às românicas, desde sua origem e formação da língua, até esclarecimento das fases do latim utilizadas em Freitas (2014).

Apontamos, ainda, a importância do latim vulgar para a análise dos termos das línguas românicas, além da divisão proposta por alguns autores, com as quais concordamos e verificamos nos dados obtidos em nossa pesquisa, principalmente em relação ao Francês.

\section{1 - România}

Etimologicamente, o termo 'românico' deriva de 'romano', gentílico de 'Roma', cujos habitantes eram chamados de 'Romani' em oposição aos habitantes da região do Lácio, 'Latini' e, posteriormente, a outros povos do Império Romano. Essa população, inicialmente pequena e dispersa em vários povoados, agrupou-se entre os séculos IV e VI a.C. por motivos religiosos; a partir do século III a.C, impôs-se sobre os demais povos, aumentando a distinção entre 'latino' e 'romano'.

Linguisticamente, todos os que falavam latim no Império Romano eram chamados 'romanos'; por conseguinte, surgiu a denominação 'Romania', que designava o conjunto de territórios onde se falava latim, e depois, as línguas românicas. Após a queda do império romano, os termos 'Romanus' e 'Romania' restringiram-se ao campo linguístico e cultural. $\mathrm{O}$ adjetivo 'Romani' designava os que falavam uma língua derivada do latim; o advérbio 'Romanice' ganhou significado de 'língua vulgar (VÄÄNÄNEN, 1971 [1967], p. 33). Para Bassetto (2010 [2005]), o significado cultural da expressão Romana Lingua mostra a existência de novas línguas distintas do latim, como registra o texto "Juramentos de Estrasburgo"; há, ainda, o termo 'romanicu', que remete à idéia cultural e linguística românica, e 'romance', que passou a designar as variedades linguísticas do latim. 
No português, por exemplo, de 'romancium', do latim medieval, originou-se 'romanço'. Na Idade Média, esse termo passou a designar as obras literárias escritas nas línguas românicas, muitas ao alcance do povo, os quais não tinham acesso às escritas em latim, visto serem restritas aos mais cultos. $O$ termo teve um alargamento semântico no final do século XVI, passando a designar não somente a língua utilizada, mas também o próprio texto escrito: o movimento romântico firmou-se como estilo, originando novos campos semânticos ao redor de 'romano'.

A denominação 'România' foi utilizada em regiões do antigo Império Romano; é o caso da Romênia, em que nome do país se derivou diretamente desse conceito. Há ainda algumas alterações metonímicas do termo, como 'român' com o sentido de pastor e escravo, e muitos derivados, restringindo seus exemplos ao Português: romagem, romanceiro, romanesco etc. Deste modo, é clara a influência exercida por Roma, não só como capital política, mas também religiosa, indicando ser esse o mundo com o qual a Filologia Românica se relaciona (KREFELD, 2004).

\section{2 - Fases do latim}

Conforme Väänänen (1971 [1967]), embora propor uma classificação cronológica do latim seja algo arbitrário, o autor o faz por meio de textos datados, relacionando-os aos acontecimentos do Império Romano. Será por meio dessa classificação, unida às de Perrot (1961) e de Roediger (1904), portanto, que a pesquisa nortearse-á para, posteriormente, datar e classificar qual o latim das palavras analisadas:

a. arcaico: desde as origens até final do século II a.C.

b. pré-clássico: final do século II a.C até a metade do século I a.C.

c. clássico (idade de ouro): metade do século I a.C. até o ano 14 d.C (morte de Augusto).

d. pós-clássico (idade de prata): 14 d.C. a 200 d.C14.

e. tardio (baixo latim): 200 d.C. ate a chegada das línguas românicas (Juramento de Estrasburgo - 842 d.C.).

\section{3 - Latim vulgar}

É mister consideramos o latim vulgar para compreendermos a origem das línguas românicas. Para isso, abordamos o contexto em que essa variedade do latim se desenvolveu e os fatores que propiciaram esse desenvolvimento. Língua itálica, pertencente à família indoeuropeia, do subgrupo Centum, originada em Roma, localizada na região do Lácio e falada pelos camponeses e pastores. "Lengua de Roma tanto como el Francês lo es de París, el latín es, sin embargo, el resultado de una fusión de elementos rústicos y extranjeros con el fondo indígena y

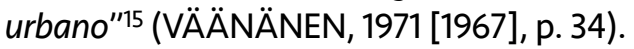

Embora fosse a língua dos dominadores, a latinização não teve a mesma intensidade em todas as localidades; no Oriente, foi superficial; na Britânia e nos Agri Decumates não ocorreu assimilação total, ainda que haja muitas marcas latinas por toda parte; na Hispânia e na Sardenha demorou cerca de dois séculos para uma romanização efetiva. Mesmo assim, o latim influenciou e foi influenciado por todas as línguas autóctones, principalmente no léxico do latim vulgar. $O$ aumento da riqueza devido às conquistas da população romana e o desenvolvimento da cultura refletiram-se na língua, diversificando-a em distintas normas linguísticas, geralmente bem documentadas.

Em suas primeiras conquistas, os romanos devastavam as cidades atacadas e levavam seus habitantes para Roma, cuja população, mesmo com o abandono desse costume pelos romanos, aumentou bastante. A distância entre a classe baixa (plebe) e a alta (patrícios, militares, dirigentes) aumentou, refletindo o hiato na língua. Acentuou por volta do século IV, devido ao crescente refinamento cultural das classes altas. A partir de então, identificam-se duas normas linguísticas: o sermo urbanus, linguagem do estrato social mais culto, e o sermo plebeius, linguagem da massa popular sem acesso à cultura, de onde emerge o latim vulgar e da qual se podem distinguir o sermo rusticus (dos camponeses pastores), o castrensis (militar) e o peregrinus (dos estrangeiros).

\footnotetext{
${ }^{14}$ Esta fase foi dividia em dois períodos na análise das palavras latinas: época de Trajano (14 d.C. a 117 d.C) e o século dos Antoninos (117 d.C. a 192 d.C)

15 "Língua de Roma tanto quanto o francês o é de Paris, o latim é, no entanto, o resultado de uma fusão de elementos rústico e estrangeiros com fundo indígena e urbano." (Tradução nossa).
} 


\section{4 - Línguas românicas}

Conforme Vidos (2001 [1956]) e Malkiel (1993), Schuchardt concluiu que não era possível chegar a uma classificação científica para distinguir as línguas românicas, dado não haver critérios adequados. Embora haja diferenças significativas para serem nomeadas irmãs, elas possuem a mesma natureza, mesma origem, e não há estabelecimento de classes no sentido próprio do termo. Alguns autores, como Diez (1973 [1874]), Ernout (1953, [1926]), Maurer Jr. (1951), Meillet (1948), Meyer-Lübke (1926), dentre outros, também propuseram diversas classificações, tanto para línguas quanto para dialetos, mostrando quão relativo é o assunto, ainda que seja baseado em critérios linguísticos.

Com tantas hipóteses, de acordo com Krefeld (2004), Amado Alonso, em sua obra "Estudos Linguísticos" (1951), propôs a România Contínua, em que buscou novos critérios: partindo do caráter ibérico ou gálico do catalão, chegou à conclusão de que as línguas de ambos os lados dos Pirineus apresentam um parentesco especial na fonética, na gramática e no léxico, ou seja, o catalão, o aragonês, o gascão e o provençal. Também chegou a dois critérios: grau de latinização inicial e grau de fidelidade posterior à tradição latina; no segundo, leva em conta a época da latinização, a distância em relação a Roma, nível cultural do povo conquistado, resistência oposta à penetração da cultura latina, variação do esforço do colonizador romano, entre outros.

Alonso apontou também um valor relativo na divisão de România Oriental e Ocidental; isola o romeno e o dalmático, que constituem o ramo oriental a partir do século IV, e inclui o italiano nas línguas ocidentais. Também separa o francês a partir do século $\mathrm{VI}$, por ter sofrido influência dos francos, germanos sem romanização anterior, fazendo que esta se afaste do provençal, catalão, castelhano (KREFELD, 2004; BASSETTO, 2010; MEIER, 1973).

Todos estes aspectos são observáveis nos corpora obtidos e nas análises feitas nas línguas escolhidas para este trabalho: observamos uma separação, por exemplo, do francês, em relação à demais línguas pesquisadas, pois há um mecanismo diferente não somente na construção das palavras, mas também na relação semântica entre elas; o romeno é uma língua que obtém as palavras derivadas em -mânt/-ment de outras línguas (primordialmente do francês) e sua produção própria ocorre por meio do alomorfe -mânt, de forma não tão intensa. O italiano, ao lado do português e do castelhano, possui muitas derivações em comum, além de ocorrer uma alteração na vogal temática de verbos de $2^{\mathrm{a}}$ conjugação de forma idêntica àquelas.

\section{Método histórico-comparativo}

A linguagem é uma herança social e sua história estende-se por séculos, por isso acreditamos que um estudo detalhado de seu funcionamento feito sob um olhar diacrônico vai ao encontro do que pesquisamos. Para este trabalho, valemo-nos do método histórico-comparativo, visto que por meio dele podemos determinar o terminus a quo (base latina) para chegarmos ao terminus ad quem (línguas resultantes do latim). Assim, estabelecemos uma relação harmoniosa entre sincronia e diacronia, empregada na romanística, por conhecermos a origem das línguas (mais complexa, por exemplo, na germanística ou eslavística), tornando o campo românico um laboratório vasto para pesquisas regidas pelos princípios da indução.

A Filologia Românica tem como objeto as línguas e dialetos românicos, ou seja, aqueles que se originaram do latim. Se uma palavra existe em várias línguas românicas, é possível indicar com precisão sua forma no latim vulgar: '*excappare' (forma suposta do latim vulgar, ainda não encontrada em uma fonte escrita que a comprove) > escapar (português, castelhano, catalão e provençal), échapper (francês), scappare (italiano) e scăpa (romeno). Caso algum fenômeno seja apresentado particularmente em uma ou outra língua, não é possível generalizá-lo, somente afirmar que talvez seja um caso isolado, ainda que possa ter sua origem no latim.

Deste modo, utilizamos o método histórico-comparativo, em razão de o terminus a quo e o terminus ad quem utilizados como corpus deste trabalho serem bem conhecidos e documentados. Esse método é aplicável a grupos de línguas genealogicamente comuns, como as românicas. Por meio desse método, a partir da comparação das línguas românicas francês, castelhano, italiano, romeno e português, será possível verificar entre elas empréstimos, justificando sua correspondência, pois "es indiscutible que el método comparativo, con todas las restricciones que se imponen a su respecto, enriquece y precisa nuestros conocimientos del latín popular" (VÄÄNÄNEN, 1971 [1967], p. 48). A fim de encontrar suas formas originárias, determinar seus metaplasmos, verificar seus significados, formação de novos campos semânticos e outras questões, seus dados foram colhidos e comparados entre si. 
Portanto, esta pesquisa é norteada pelo comparativismo, ou seja, a técnica de pesquisa na gramática histórica por meio da comparação das palavras e estruturas gramaticais de línguas que possuem uma origem comum, com o objetivo de se estabelecerem a origem, o étimo, a datação e as derivações ocorridas das palavras latinas derivadas em -men e -mentum em algumas línguas românicas e no latim.

Este trabalho é suporte para se compreender a origem do sufixo-mentum latino; observar como as palavras latinas terminadas em -mentum se comportam nas línguas românicas; como o sufixo -mentum latino formou, dentro de cada língua observada, outras novas derivações semânticas, para verificarmos as dinâmicas ocorridas nessas línguas aparentadas, a partir da datação e da semântica das palavras românicas, a fim de estabelecermos uma grande árvore genealógica e indicarmos uma provável constelação sufixal ${ }^{16}$ do sufixo -men latino.

\section{Formação dos corpora}

Para esta pesquisa, foi necessária uma bibliografia composta por: trabalhos de história da língua latina, das línguas românicas em geral; etimologia; dicionários, inclusive os históricos, com possíveis datações e etimologia das palavras formadas com o sufixo nas várias línguas em que ele ocorre; gramáticas históricas; trabalhos específicos de morfologia sincrônica e diacrônica, bem como de semântica.

O estudo das línguas apontadas neste trabalho foi baseado em corpora obtidos a partir de vocabulários e dicionários etimológicos, e de língua geral das românicas, em outros sítios de pesquisa, como o "Corpus do Português", "Corpus del Español"; adicionalmente, levantamos uma bibliografia publicada até o presente sobre etimologia, morfologia derivacional, relação semântica entre sufixos, a fim de complementarmos o corpus para o trabalho.

Para montagem inicial dos corpora, seguimos a metodologia especificamente desenvolvida pelo GMHP:

(...) para a compreensão do fenômeno da polissemia afixal. Suspende-se, em nossas análises, momentaneamente, o conceito saussuriano de langue, à medida que se investigam diversos sistemas à procura de soluções específicas. Esses sistemas podem, portanto, pertencer à mesma língua (atraindo assim problemas de Dialetologia e Sociolinguística), de línguas afins (valendo-se da Filologia ou Linguística Românica) ou de outras línguas envolvidas (quer na difusão do étimo, quer no empréstimo da palavra ou dos morfemas gramaticais, valendo-se da História Geral). Não trabalhando com o Português como langue, mas como resultado pancrônico de heranças lexicais, avalia-se, porém, em diversas sincronias, a gênese dos elementos estudados, bem como os sistemas de relações, as heranças e as analogias que explicam a polissemia atual dos formantes em cada momento. Dessa forma, é possível fazer uma revisão bastante considerável nos métodos diacrônicos (principalmente no que toca à reconstrução e seus graus de certeza), suas ferramentas e, com base na Historiografia, o momento adequado de sua implementação. Com isso, o estudo diacrônico promove indiretamente uma reflexão sobre o método sincrônico, à medida que se questiona, em nosso método, sobretudo, a capacidade do falante nativo de fornecer impressões acertadas acerca de sua língua materna que condigam com a formação da estrutura estudada, bem como do sistema sincrônico atual. Para isso, prescinde-se completamente de regras dedutivas de formação de palavra - quer as tradicionais, quer as RFP ou quaisquer outras suposições tácitas, como a de que palavras derivadas provenham das simples, cf. caso colação e colar grau, em que a primeira é mais antiga que a segunda: nesse caso 'simples' e 'derivado' é meramente terminológico e não tem referencialidade. Também a competência do falante para decidir questões de gramaticalidade é substituída, sem perda de objetividade, pela interpretação do evento, com base em dados, uma vez que, abandonando a langue, não seria possível que nenhum falante consiga ver o todo e, dessa forma decidir sobre questões de gramaticalidade ou composicionabilidade. (VIARO, 2006b).

Traçamos um mapeamento geral do significado semântico das palavras derivadas por esses sufixos no latim, datando esses significados, com o objetivo de montarmos uma árvore genealógica de ambos e provarmos que há uma constelação sufixal, cujos elementos se derivam do sufixo latino -mentum; esses significados foram

\footnotetext{
16 Usa-se o termo lexicalizado 'constelação sufixal' conforme Aréan-García (2012).
} 
comprovados em corpora, conforme indicação no corpus de cada língua analisada, para autenticarmos seu comportamento semântico, bem como as relações paradigmáticas e composicionais nas palavras formadas por esses sufixos nas línguas românicas, com o objetivo de propor uma classificação semântica, diacrônica e contrastiva.

Examinamos os dados obtidos nas línguas românicas, sob um olhar diacrônico; a partir disso, elaboramos uma lista, com o objetivo de verificarmos, rigorosamente, a utilização das palavras. Ao final, o estudo resultou em um corpus preciso da formação derivacional de palavras terminadas nesses sufixos, observando seus valores semânticos nas línguas latina, portuguesa, castelhana, francesa, italiana e romena.

Em cada língua, recolhemos as palavras terminadas em: cast. -mento / -miento / -menta / -mienta; fr. -ment; it. -mento; rom. - mânt / - ment; port. - mento / - menta. Em seguida, após pesquisa, indicamos a data de sua criação, o étimo, "forma equivalente da mesma palavra, imediatamente anterior numa sincronia pretérita qualquer" (VIARO, 2011, p. 99), a língua de origem e a primeira acepção semântica da palavra, dados primeiramente recolhidos na microestrutura das obras lexicográficas utilizadas para compor o corpus em cada uma das línguas e, em seguida, informações obtidas em outras fontes, apontadas durante a descrição de composição de cada corpus de análise.

Durante o desenvolvimento das listagens, identificamos se as palavras são, de fato, derivadas no sufixo tema desta pesquisa; excluímos possíveis terminações coincidentes, por exemplo: ciumento: de ciúmes + -ento. Também deixamos fora de nosso corpus de análise as palavras compostas, devido ao nosso objetivo ser analisar o significado do sufixo latino -mentum e de seu desenvolvimento nas românicas; em uma palavra formada por composição, não há derivação, por exemplo: biodesenvolvimento: bio- + desenvolvimento. Importante informar que, pelo mesmo motivo, não consideramos palavras prefixadas, desde que indicada a formação no dicionário, como desabastecimento: des- + abastecimento.

Após a elaboração de corpora, análise das palavras e comparação entre as línguas, formamos uma pequena árvore genealógica para cada lista de palavras desenvolvida, por língua analisada, para compararmos as classificações e as árvores das várias línguas observadas e apontarmos cada ligação com a classificação e árvore genealógica latina. Ao final, apresentamos os dados comparativos obtidos e as justificativas que defendam as hipótese elaboradas.

\section{Análise quantitativa}

Em todas as línguas, exceto no latim, por indicarmos de modo exaustivo todos os étimos e respectivas origens das palavras analisadas naquela língua, após apresentarmos como formamos o corpus de análise e apontarmos algumas características de cada língua em especial, indicamos a quantidade de palavras encontradas em cada terminação do sufixo estudado com as vogais temáticas ' $a$ ', ' $e$, ' ' $i$ ', outras possibilidades de vogais, como ' $o$ ' e ' $u$ ' e outras terminações, como consoantes antes do sufixo. Com isso, nossa hipótese foi comprovar a proporção de palavras oriundas das formas latinas, por exemplo, as com bases terminadas em consoantes (também latinas), como segmento, ou ainda palavras com base terminada em uma falsa vogal temática latina em ' $e$ ' (elemento), encontradas em todas as línguas pesquisadas, provando serem palavras panromânicas, ou seja, palavras que o latim deixou como herança em todas as línguas latinas.

Paralelamente, apontamos para cada item alguns exemplos de formações e a porcentagem de palavras encontradas em relação ao corpus como um todo.

\section{Datação}

Com o objetivo de observarmos a produtividade do sufixo -mento em cada língua analisada neste trabalho, nosso corpus é composto exclusivamente por verbetes datados. Na formação de corpus de cada língua, explicamos como compusemos essas datas, já que muitas palavras estavam sem indicação da época de sua formação, principalmente as do português e do castelhano. 
$\mathrm{Na}$ listagem de cada língua, todas conservam suas datas de origem e, ao lado, o século de sua formação; por meio desses dados, montamos tabelas e gráficos que auxiliaram nas análises feitas a partir de todas as palavras e também somente daquelas formadas nas próprias línguas (sem os empréstimos).

\section{Análise semântica}

As gramáticas portuguesas informam, geralmente, que os afixos, principalmente os sufixos, são elementos semanticamente mais vazios do que, por exemplo, os radicais. Não há como concordar com a afirmação de Rocha Lima [1985 (1972)] de os sufixos serem vazios de significação, como informa em sua "Gramática normativa da língua portuguesa":

Ao contrário dos prefixos, que [...] guardam certo sentido, com o qual modificam, de maneira mais ou menos clara, o sentido da palavra primitiva, os sufixos, vazios de significação, têm por finalidade formar séries de palavras da mesma classe gramatical. (LIMA, 1985 [1972], p. 180-181).

Somente seria possível essa consideração se os sufixos fossem observados isoladamente, contudo não faz sentido fazermos um estudo dos sufixos por si só, e sim ligados a uma base, por serem responsáveis por uma alteração semântica nesta que habitualmente se depreende por meio de paráfrases, por exemplo: X-mento 'ação de X' - desenvolvimento ('ação de desenvolver').

Segundo Sandmann (1989), semanticamente os sufixos equivalem a uma paráfrase feita a partir de um processo específico de derivação, ou seja, igualam-se a lexemas; portanto, é mister que se apontem as regras de formação de palavras (RFPs) destes.

Margarida Basílio indica que as entradas lexicais em uma língua podem afetar a produtividade das RPFs:

(...) as várias restrições (morfológicas, sintático-semânticas, léxico-semânticas) que determinam a seleção de um determinado sufixo em detrimento de outro(s) têm consequências, quer ao nível da produtividade, quer ao nível da polissemia. (BASíLIO, 1980, p. 15).

De acordo com Freitas (2008), no Português há diversas formações duplas entre -mento e outros sufixos, como apontadas na seção de sufixos concorrentes, e não necessariamente há um bloqueio entre essas formas ${ }^{17}$. A pesquisadora aponta, ainda, outras formações duplas entre línguas, como cancelamento e cancellation, no Português e no Inglês respectivamente, indicando que essas formações paralelas são um "conceito sincrônico; assim, nada impede que haja, em outras épocas, formas desses exemplos em -mento e em -s/ção, respectivamente no Inglês e Português" (p. 82).

Basílio (1987, p. 5-10) ainda ressalta que "as palavras são elementos de que dispomos permanentemente para formar enunciados" e que, muitas vezes, "temos uma palavra de uma classe ou categoria lexical, como "verbo", e precisamos usá-la como "substantivo". Nesse caso, formamos uma palavra nova para poder utilizar o significado de uma palavra já existente num contexto que requer uma classe gramatical diferente".

Oliveira (2007) aponta que os sufixos do tipo - mento "denotam mudança de estado causada internamente (...) e têm como resultado uma forma derivada que denota mudança de estado". Contudo, observamos outros aspectos semânticos nas palavras derivadas em -mento: no total, quatro classes de ação e uma relacional.

Em seus artigos sobre morfologia, Rio-Torto (1998) mostra que, para analisarmos algum aspecto morfológico, devemos também utilizar todos os outros campos linguísticos. Segundo ela,

(...) a componente de base contém as estruturas básicas indispensáveis à produção de novos produtos lexicais. Essas estruturas são as bases e os afixos. (...) bases e operadores afixais devem estar descritos quanto à sua estrutura fonológico-silábica e quanto à sua estrututra morfológica, sintática, categorial e semântica. (...) a estrutura semântica de uma palavra comporta diversos níveis e tipos de significação. (RIO-TORTO, 1998, p. 75).

\footnotetext{
17 Monitoramento, monitoração e monitoragem (fetal) são formas utilizadas por um determinado plano de saúde, aleatoriamente,
} para um mesmo procedimento ambulatorial. 
No caso do sufixo estudado, o sufixo -mentum latino e os originados deste nas línguas românicas, a base é, de fato, um elemento semanticamente mais pleno de significação do que o sufixo, mas não é necessariamente verdade para todos os sufixos, por exemplo: pedreiro, poleiro, chiqueiro, palavras cujo sufixo -eiro, conforme Viaro (2004), possui mais significado que sua base, opacificada pelo tempo; do mesmo modo ocorre essa alteração em substantivos portugueses, derivados do latim, terminados em -mentum: fermento (de fermentum), lamento (de lamentum).

Ainda que alguns discordem, os sufixos podem apresentar mais de um significado, assim como as unidades lexicais. No latim, o significado de -mentum era, em geral, de 'instrumento que X', 'ação ou resultado de X'; entretanto, ao analisarmos as palavras dos corpora, observamos outros significados incorporados às palavras derivadas dos sufixos nas línguas pesquisadas, uma verdadeira polissemia.

Verificamos que as palavras em -mentum latinas e das línguas românicas possuem significado concreto e abstrato; ambas as formas derivam de uma raiz ou radical verbal, ou de um substantivo - raras são as formas que derivam, vez ou outra, de um adjetivo, por exemplo. Além disso, observamos que há na maioria sentido de 'ação' ou 'processo', em outras, significado de 'resultado de uma ação'; posteriormente, tornam-se concretas.

Para analisarmos todas essas palavras sob o ponto de vista semântico, observamos na microestrutura ${ }^{18}$ das obras lexicográficas pesquisadas qual a indicação de seu primeiro significado, para, posteriormente, classificarmos uma a uma e analisarmos suas paráfrases. Deste modo, possíveis derivações semânticas que a palavra tenha sofrido em cada língua não estão apontadas neste trabalho.

Indicamos em alguns verbetes, aparentemente não analisáveis sincronicamente, seu primeiro significado, de sua língua de origem, a fim de não falsearmos os dados, mesmo que o sentido não seja o mais usual atualmente. Entretanto, somente as palavras formadas na língua analisada estão inseridas na análise semântica; palavras que entraram na língua por empréstimos, portanto, foram descartadas dessa análise. Como nosso objetivo é investigar a semântica da produtividade do sufixo em cada uma das línguas analisadas, palavras com formação em outra língua não entram nesta análise, visto que o significado considerado seria o da língua de origem e não da analisada. Por exemplo, a base opaca de fermento (port.) < fermentum (lat.) foi analisada e considerada em Freitas (2008), mas não há como considerarmos a palavra fermento na análise das palavras portuguesas, pois seu significado foi produzido no latim. Portanto, os empréstimos foram descartados nas seções respectivas à análise semântica, devido a entrarem numa falsa porcentagem de produção na semântica analisada.

A classe MOV, (<movimento), incorporada em Freitas (2008), não foi utilizada. Analisamos todos os aspectos e as palavras sufixadas em -mento (port.) e seus referentes e concluímos que, nas línguas românicas, não há palavras em nosso estudo que possuam o comportamento de envolverem apenas o deslocamento de um ser ou, ainda, que tenham a referência apenas de seu próprio deslocamento, embora o sufixo estudado esteja apontado nessa classe: 'o fato de X', 'ação de X', 'processo de X' (-da, -mento, -s/ção, -agem) (VIARO, 2009, p. 158).

Seguem as categorias semânticas (paráfrases) encontradas e utilizadas para análise semântica dos corpora, conforme algumas classes de ação constantes em Viaro (2009):

\section{Classes de ação}

a. LCA (<local da ação) para a paráfrase 'local onde se X' (-ório, -or, -nte, -aria, -mento, -ouro);

b. INS (<instrumento) para 'instrumento (com) que (se) $x^{\prime}$, 'instrumento (com) que (se) $V$ o X' (-eiro, -ouro, -ório);

c. TRS (<transitivo) para nomina actionis em que há apenas um agente e um paciente: 'o fato de X', 'ação de X', 'processo de X' (-mento, -s/ção, -agem) ou 'transformar C em X', 'ação de transformar C em X', '(ação de) V X em', '(ação de) V C em X', '(ação de) causar X' (-ar, -izar, $a-\ldots$-ar, es-...-ar, a-...-mento, em-...-s/ção, -ficar, -ecer, -ear); idem para golpes, tanto 'golpe praticado com X', 'golpe praticado em X' (-ada);

\footnotetext{
${ }^{18}$ Neste trabalho, utilizamos os termos lexicográficos macroestrutura: as entradas, os verbetes de um dicionário, e microestrutura: 0 conteúdo de cada verbete; conforme Barbosa (1994), a macroestrutura é a organização vertical dos artigos ou entradas, por ordem alfabética, etimológica, de assuntos, de campos léxicos e semânticos (...) a microestrutura do artigo, entrada ou verbete é constituída por um conjunto de "informações" ordenadas que se seguem à entrada.
} 
d. RES (<resultado) para nomina actionis em que há grande número de elementos envolvidos na ação ou nas ações: 'o fato de $X$ ', 'ação de $X$ ', 'processo de $X$, 'estado decorrente de X' (-ada, -mento, -s/ção, -agem, -ança), mas também: 'alimento preparado com X' (-ada) e 'substância extraída de $\mathrm{X}^{\prime}(-$ ina).

Quadro 01. Classes semânticas relacionadas à 'ação' (Fonte: VIARO, 2009).

Também há, além das categorias semânticas apresentadas, uma outra, que mesmo não estando apontada na Classe de Ação, mas na Relacional, incorpora um dos aspectos encontrados em todas as línguas analisadas: o de coletivo. Desconsiderada ao final da pesquisa na língua latina, ela está incorporada aos dados das demais línguas.

\section{Classe relacional}

e. QNT (<quantidade) para os coletivos e outros nomina quantitatis 'conjunto de $X^{\prime}$, 'quantidade de X' (-agem, -ada, -ame, -edo, -io, -aria, -ugem).

Quadro 02. Classe semântica relacionada à 'quantidade' (Fonte: VIARO, 2009).

Apesar de o aspecto QNT estar indicado na classe relacional, nossa hipótese é a de que as palavras em mento que indiquem coletivo ou quantidade tenham traços transitivos e agentivos, talvez por serem deverbais e se constituírem sempre por meio de algo ou alguém que faça a ação originária.

Além dessas análises, apresentamos duas propostas novas no francês, resultantes da observação do corpus nesta língua: CRI, 'grito de Y', em que Y é um bicho, e BRU, 'barulho de Y', em que Y é um substantivo concreto ou abstrato. As palavras inseridas nessas acepções são em número maior que as indicadas, por exemplo, em INS, QNT e LOC, portanto não poderíamos descartá-las. Foi necessária uma pesquisa e análise mais aprofundada, a fim de confirmarmos a hipótese de serem acepções diferentes das demais apresentadas neste trabalho para, ao final, apresentarmos a derivação em -ment no francês com funcionamento diferente das demais línguas românicas.

\section{Sufixos concorrentes}

Uma língua não é imutável. Do mesmo modo como ocorrem alterações contínuas em outras partes (radicais, desinências), os sufixos são submetidos a influências variadas, não somente ortográficas: seus significados originais dissolvem-se e podem surgir, ocasionalmente, novos significados que repelem completamente os originais. Mesmo assim, essa circulação entre os limites é somente possível nos sufixos cujos significados possuem a mesma relação familiar, como em diversas palavras cognatas em -mento e -ção, no português (

Analisamos as palavras formadas pelo sufixo -mento nas suas variações nas línguas analisadas e os cognatos encontrados nas obras lexicográficas utilizadas para a recolha dos verbetes em cada língua pesquisada, a fim de observarmos as palavras formadas por alguns sufixos concorrentes, ou seja, por sufixos com mesmo sentido, significado, função, isto é, palavras cujos sufixos apresentem "distintividade fonológica e identidade funcional e semântica" (CAETANO, 2008, p. 1).

No português, não desenvolvemos tal análise neste trabalho, devido à intensa pesquisa feita sobre esse assunto feita em Freitas (2008). Acreditamos que se a refizéssemos, somente repetiríamos os dados obtidos na pesquisa anterior, não havendo informações novas e/ou inéditas a respeito.

Se observarmos "do ponto de vista do sistema, concorrentes são dois sufixos com a mesma função. Isso ocorre, portanto, com os núcleos semânticos de um dado sufixo e não com o sufixo em sua integralidade" (VIARO, 2007, p. 17). Limitamo-nos às microestruturas das obras pesquisadas para podermos comparar as palavras como concorrentes e imaginar haver um conjunto de traços, ou seja, de semas em comum (POTTIER, 1978, p. 29), isto é, palavras que sejam sinônimas. Se fôssemos buscar todas as palavras cognatas na macroestrutura das obras lexicográficas, com certeza o resultado seria muito maior que o obtido, porém muitas, apesar de possuírem mesma base com sufixos diferentes, não teriam significados parecidos e, portanto, não seriam palavras 
concorrentes, ou seja, palavras que, no nosso entendimento, tenham sido criadas com a mesma finalidade, mesmo objetivo de uso.

Indicamos os séculos das formações do sufixo -mento paralelamente à formação cognata encontrada em cada língua. Encontramos muitos sufixos concorrentes, os quais estão indicados nas respectivas línguas, conforme a quantidade encontrada. Ao final, apresentamos uma comparação entre essas concorrências, pois verificamos que a língua francesa apresenta cognação diferente das demais línguas analisadas neste trabalho.

\section{Considerações finais}

As línguas podem se alterar num mesmo tempo, ou seja, podem apresentar variações ocorridas devido a alguns fatores específicos, por exemplo pelo estrato social, etário, geográfico etc. Portanto, não podemos impor o certo e errado quando uma análise observa o desenvolvimento de uma língua; este estudo histórico, como qualquer outro estudo científico, aponta para essa questão e se torna material importante para a descrição e explicação diacrônica, principalmente etimológica, dos sufixos pesquisados nas línguas românicas e, principalmente, de suas origens, para então observar os existentes na língua portuguesa.

A execução do projeto foi facilitada pela nossa familiaridade com o tema, principalmente pelo desenvolvimento da pesquisa feita em Freitas (2008; 2014); além disso, nossa formação filológica e românica auxiliou a pesquisa, principalmente bibliográfica.

Estudamos, pois, os vários aspectos das formações derivacionais do sufixo latino -mentum, a fim de verificarmos os aspectos semânticos relevantes deste em todas as línguas que dele se originaram. A partir da comparação linguística, da etimologia e da datação, bem como das mudanças que, por ventura, ocorreram no âmbito linguístico, fizemos uma classificação semântica das palavras formadas com esses sufixos naquela língua e, em seguida, um estudo de suas relações com as formações derivadas nas românicas, sobretudo no âmbito semântico, dando continuidade ao trabalho de mestrado que forneceu as características semânticas do sufixo mento no português e uma metodologia de pesquisa para tal finalidade.

Após a obtenção das informações sobre a origem do sufixo latino -mentum e de suas derivações às românicas, percebemos quão necessários são os estudos linguísticos que se voltem para a diacronia; mais ainda aqueles cujo objetivo seja incorporar vários fatores, inclusive com relação à proximidade dos falares de regiões que compartilham um passado linguístico comum. Pesquisas diacrônicas que foquem os aspectos semânticos comparativos entre as línguas românicas, como o estudo do sufixo - mentum em contraste com seus derivados nas línguas aparentadas, serão sempre colaborativas para que haja uma melhor compreensão do desenvolvimento de línguas irmãs.

\section{Referências bibliográficas}

BARBOSA, M. A. Dicionário de língua, vocabulários técnico-científicos, glossários: estatuto semântico-sintáxico das unidades-padrão. In: Anais do XLI Seminário do GEL. Ribeirão Preto: GEL, 1994. p. 289-294.

BASÍLIO, M. Estruturas lexicais do português. Petrópolis: Vozes, 1980. Teoria lexical. São Paulo: Ática, 1987.

BASSETO, B. F. Elementos de filologia românica. 2. ed. São Paulo: EDUSP, 2010 [2005] . COROMINAS, J. Diccionario crítico etimológico de la lengua castellana. 6 tomos, 3. ed. Madrid: Gredos, 1954. CORPUS DEL ESPAÑOL. Disponível em: <www.corpusdelespanol.org>. Acesso em: 20 jun. 2015. CORPUS DO PORTUGUÊS. Disponível em <www.corpusdoportugues.org>. Acesso em: 20 jun. 2015.

DIEZ, F. Grammaire des langues romanes. 3. ed. Geneve: Slatkine, 1973 [1874].

DUBOIS, J. et al. Dicionário de Linguística. 8. ed. São Paulo: Cultrix, 2001 [1973].

ERNOUT, A. Morphologie Historique du Latin. 3. ed. Paris: C. Klincksieck, 1953 [1926].

FREITAS, E. S. S. Em busca do mento perdido. Análise semântico diacrônica do sufixo -mento, no português. Dissertação (Mestrado em Filologia e Língua Portuguesa). FFLCH, Universidade de São Paulo, São Paulo: 2008.

FREITAS, E. S. S.; AREÁN-GARCÍA, N. Morfologia histórica do português. Revista Philologus, ano 16, no 47, p. 109-118, 2010. Disponível em: <http:// www.filologia.org.br/revista/47/07.pdf>. Acesso em: 20 jun. 2015.

GOOGLE BOOKS. Disponível em: <http://books.google.com.br/>. Acesso em: 20 jun. 2015. 
GRUPO DE MORFOLOGIA HISTÓRICA DO PORTUGUÊS (GMHP). Disponível em: <www.usp.br/gmhp>. Acesso em: 20 jun 2015.

GRANDE DICIONÁRIO HOUAISS DA LÍNGUA PORTUGUESA. Versão ßeta. Rio de Janeiro: Objetiva, 2009. Disponível apenas para assinantes em: <http://houaiss.uol.com.br>. Acesso em: 20 jun. 2015.

HOUAISS, A.; VILLAR, M. S. Dicionário Houaiss da língua portuguesa. Rio de Janeiro: Objetiva, 2001, CD-Rom.

KREFELD, T. Le roumain et la Romania continua. In: ICHIM, O.; OLARIU, F. T. (Org.). Spațiul lingvistic şi literar românesc din perspectiva integrării europene, Mănucă Dan/laşi, 2004. p. 62-72. Disponível em: <http:// www.romanistik.uni-muenchen.de/downloads/links_personen/kr efeld/krefe ld-iasi.pdf>. Acesso em: 20 jun. 2015.

LIMA, R. Gramática normativa da língua portuguesa. Rio de Janeiro: José Olímpio, 26. ed., 1985 [1972].

MALKIEL, Y. Etymology. New York: Cambridge University Press, 1993.

MAURER Jr., T. H. Unidade da România Ocidental. São Paulo: USP, 1951.

MEIER, H. Ensaios de Filologia Românica. 2. ed. Rio de Janeiro: Grifo,1973.

MEILLET, A. Linguistique historique et linguistique generale. Paris: Champion, 1948.

MEYER-LÜBKE, W. Introducción a la linguística românica. Madrid: Casa Edit. Hernando, 1926.

NÚCLEO DE APOIO À PESQUISA EM ETIMOLOGIA E HISTÓRIA DA LÍNGUA PORTUGUESA (NEHiLP). Disponível em: <www.usp.br/nehilp>. Acesso em: 20 jun. 2015.

OLIVEIRA, S. M. Os sufixos nominalizadores -ção e -mento. Estudos linguísticos XXXVI. Araraquara. Janeiro-Abril, p. 87-96, 2007.

PERROT, J. Les dérivés latins em -men et -mentum. Paris: C. Klincksieck, 1961.

POTTIER, B. Línguística geral: teoria e descrição. Trad. Walmírio Macedo. Rio de Janeiro: Presença / Universidade Santa Úrsula, 1978.

RIO-TORTO, G. M. Formação de palavras em português. Aspectos da construção de avaliativos. Tese (Doutorado em Linguística). Faculdade de Letras, Universidade de Coimbra, Coimbra, 1993.

. Morfologia Derivacional: Teoria e aplicação ao português. Porto: Porto Editora, 1998.

ROEDIGER, M. Die Bedeutung des Suffixes "ment". Weimar: R. Wagner, 1904.

SAID ALI, M. Gramática Histórica da Língua Portuguêsa. São Paulo: Melhoramentos, 1964 [1931] .

SANDMANN, A. J. Competência lexical. Curitiba: UFPR, 1988.

SAUSSURE, F. Cours de linguistique générale. Édition critique par Tullio de Mauro. Paris: Saint-Germain, 1995 [1916].

VÄÄNÄNEM, V. Introducctión al latín vulgar. Versión española de Manuel Carrión. Madrid: Gredos, 1971 [1967].

VIARO, M. E. Por trás das palavras. Manual de etimologia do português. São Paulo: Globo, 2004.

Para um estudo de semântica sincrônica dos sufixos derivacionais em português do século XIII. In: Estudos

lingüísticos, Taubaté: Unitau, 2006a, com. 95, CD-Rom. Disponível em: <http://www.usp.br/gmhp/publ/ Via21.pdf>. Acesso em: 20 jun. 2015.

. Pressupostos. In: GMHP - Grupo de Morfologia Histórica do Português. FFLCH-USP, 2006b. Disponível em :

<www.usp.br/gmhp/pres.html>. Acesso em: 20 jun. 2015.

. Problemas de morfologia e semântica histórica do sufixo -eiro. Estudos Línguísticos. São Paulo. v. 35, p.

1443-1452, 2006c.

Estudo diacrônico da formação e da mudança semântica dos sufixos -eiro/-eira na língua portuguesa. In:

MASSINI-CAGLIARI, Gladis et alii (Org.). Trilhas de Mattoso Câmara e outras trilhas: fonologia, morfologia, sintaxe.

São Paulo: Cultura Acadêmica, 2007, Série Trilhas linguísticas n. 12. p. 45-84.

Proposta de um método de análise para derivações sufixais. Domínios de Lingu@gem. Revista Eletrônica de

Linguística. Ano 3, n. 2, p. 140-165, 2009. Disponível em: <http://www.dominiosdelinguagem.org.br/pdf/dl6/DL

\%206\%20-\%2010.pdf >. Acesso em: 20 jun. 2015.

Etimologia. São Paulo: Contexto, 2011.

VIDOS, B. E. Manual de Linguística Românica. Vol I - História e metodologia. Trad. J. P. Silva. 2. ed. Rio de Janeiro:

Edição do tradutor, 2001 [1956]. 